\title{
The Major Specificity-Determining Amino Acids of the Tomato Cf-9 Disease Resistance Protein Are at Hypervariable Solvent-Exposed Positions in the Central Leucine-Rich Repeats
}

\author{
Brande B. H. Wulff, ${ }^{1}$ Antje Heese, ${ }^{1}$ Laurence Tomlinson-Buhot, ${ }^{1}$ David A. Jones, ${ }^{2}$ Marcos de la Peña, ${ }^{3}$ \\ and Jonathan D. G. Jones ${ }^{1}$ \\ ${ }^{1}$ The Sainsbury Laboratory, John Innes Centre, Norwich Research Park, Colney Lane, Norwich NR4 7UH, U.K.; ${ }^{2}$ The \\ School of Biology, The Australian National University, Canberra ACT 0200, Australia; ${ }^{3}$ Instituto de Biología Molecular y \\ Celular de Plantas (UPV-CSIC), Avenida de los Naranjos, s/n, 46022 Valencia, Spain
}

Submitted 15 December 2008. Accepted 24 April 2009.

The interaction between tomato and the leaf mold pathogen Cladosporium fulvum is controlled in a gene-for-gene manner by plant $C f$ genes that encode membrane-anchored extracytoplasmic leucine-rich repeat (LRR) glycoproteins, which confer recognition of their cognate fungal avirulence (Avr) proteins. $\mathrm{Cf}-9$ and $\mathrm{Cf}-4$ are two such proteins that are $91 \%$ identical yet recognize the sequence-unrelated fungal avirulence determinants Avr9 and Avr4, respectively. As shown previously, $\mathrm{Cf}-4$ specificity is determined by three putative solvent-exposed residues in the central LRR and a deletion of two LRR relative to $\mathrm{Cf}-9$. In this study, we focused on identifying the specificity determinants of $\mathrm{Cf}-9$. We generated chimeras between $\mathrm{Cf}-9$ and its close homologue $\mathrm{Cf}-9 \mathrm{~B}$ and identified five amino acid residues that constitute major specificity determinants of Cf-9. Introduction of these residues into $\mathrm{Cf}-9 \mathrm{~B}$ allowed recognition of Avr9. Consistent with a role in recognition specificity, the identified residues are putatively solvent exposed in the central LRR and occupy hypervariable positions in the global Cf alignment. One of the specificity residues is not found in any other known Cf protein, suggesting the importance of diversifying selection rather than sequence exchange between homologues. Interestingly, there is an overlap between the $\mathrm{Cf}-4$ and $\mathrm{Cf}-9$ specificity-determining residues, precluding a protein with dual specificity.

Receptor-like proteins (RLP) and receptor-like kinases (RLK) form an important structural group of plant proteins which govern interaction with symbiotic and pathogenic microbes and also diverse processes in development. In Arabi-

Corresponding author: J. D. G. Jones; E-mail: jonathan.jones@ sainsburylaboratory.ac.uk; Fax +44-1603-450011.

Present address of B. B. H. Wulff: Institut de Biologie Moléculaire des Plantes (IBMP-CNRS), 12 rue du Général Zimmer, 67084 Strasbourg, France.

Present address of A. Heese: University of Missouri-Columbia, Department of Biochemistry, 540G Christopher S. Bond Life Sciences Center, 1201 Rollins Road, Columbia 65211-7310, U.S.A.

*The e-Xtra logo stands for "electronic extra" and indicates that additional materials and methods, two supplementary figures, and PDB file information are published online. dopsis, approximately $1 \%$ of the protein-encoding genes are RLP or RLK (Fritz-Laylin et al. 2005; Shiu et al. 2004). Typically, these are membrane-anchored proteins carrying an extracellular ligand-detection domain and a short cytoplasmic tail (in the case of RLP) or a cytoplasmic kinase domain (in the case of RLK).

In tomato, homologues of $C f-9(\mathrm{Hcr} 9 \mathrm{~s})$ that confer resistance to the leaf mold fungus Cladosporium fulvum belong to a multigene family encoding RLP (Parniske et al. 1997). Hcr9 RLP recognize the presence of cognate proteins of the fungus that are secreted into the apoplast during the infection process where, most likely, they serve as effectors to promote pathogen fitness (Thomma et al. 2005; Van Esse et al. 2007). Their recognition is highly specific and activates plant defenses to effectively curb fungal growth. This type of gene-for-gene recognition is typically overcome by jettison or structural alteration of the effector through mutation, while the presence of indispensable effectors may be masked by employing yet another effector to interfere with resistance $(R)$ gene function (Jones and Dangl 2006).

The strictly extracellular lifestyle of $C$. fulvum has allowed the facile isolation and characterization of several of the fungal race-specific elicitors from apoplastic washing fluids of infected leaves (Joosten and de Wit 1999). These fungal elicitors are characterized by being small, secreted, cysteine-rich proteins but, unlike the Hcr9 resistance proteins, the fungal effector proteins are sequence unrelated.

The bulk of the Hcr9 resistance proteins consist of extracellular glycosylated leucine-rich repeats (LRR). LRR have been shown in many species to mediate specific protein-protein interactions (Kobe and Deisenhofer 2001). The bean polygalacturonase inhibitor protein (PGIP) is the only protein with extracellular LRR whose structure has been determined (di Matteo et al. 2003). As is typical of LRR proteins from other organisms (Kobe and Deisenhofer 2001), the repeated $\beta$ strand/ $\beta$-turn motif of the LRR line up to form a $\beta$-sheet available for ligand interaction. The conserved leucines project into the hydrophobic core of the protein while the interstitial amino acids, which vary between adjacent LRR, are solvent exposed. In PGIP, mutation of one of these solvent-exposed interstitial residues can change specificity (Leckie et al. 1999). When the LRR of Hcr9 homologues are aligned, the most variable amino acid positions coincide with the putative solvent-exposed positions, indicating that diversifying selection is operating at the 
residues in these positions (Parniske et al. 1997). This is consistent with these residues being involved in recognition of rapidly evolving elicitors. However, no evidence has been found for a direct interaction between a tomato Hcr9 resistance protein and its cognate $C$. fulvum elicitor.

The alignment of $\mathrm{Hcr} 9 \mathrm{~s}$ has revealed evidence for extensive past intragenic recombination between different $\mathrm{Hcr} 9$ paralogs (Parniske and Jones 1999; Parniske et al. 1997; Van der Hoorn et al. 2001a). This reshuffling of LRR sequences also has the potential to create new recognition specificities. Finally, LRR copy number varies significantly between Hcr9s and differences in the number of LRR may also be an important determinant of specificity (Seear and Dixon 2003; Van der Hoorn et al. 2001b; Wulff et al. 2001).

An understanding of the determinants of $R$-gene specificity is important because this may yield inferences about the modus operandi of $R$ genes and pave the way for the future engineering of synthetic $R$ genes. Several rapid and quantitative assays are available to analyze tomato $\mathrm{Hcr} 9$ function (Thomas et al. 2000; Van der Hoorn et al. 2000). Furthermore, many functional $H c r 9 s$ with the same or different specificities have been cloned along with their cognate fungal elicitors (Rivas and Thomas 2005), making this a choice system to study plant extracellular LRR specificity determination. Cf-4 and Cf-9 are $>91 \%$ identical (Thomas et al. 1997) and recognize the sequence-unrelated Avr4 and Avr9 elicitors (Joosten and de Wit 1999). Differences between Cf- 4 and Cf- 9 are largely confined to 66 amino acid polymorphisms in the LRR and a deletion of two full LRR in Cf-4 corresponding to LRR 11 and 12 in Cf-9.

Previously, by making chimeras between Cf- 4 and Cf-9, we and others identified the specificity determinants of Cf-4 to include the LRR copy number polymorphism (Van der Hoorn et al. 2001b; Wulff et al. 2001) and three putative solventexposed residues in the central LRR (Van der Hoorn et al. 2001b). However, Cf-9 specificity appeared to be spread over several LRR, making it difficult to pinpoint single residues as major determinants of specificity. In the present study, this difficulty was overcome by making chimeras between Cf-9 and its close paralog, Cf-9B. $C f-9 B$ is a functional resistance gene that confers adult plant resistance against strains of $C$. fulvum expressing Avr9B (Panter et al. 2002; Parniske et al. 1997), although the identity of Avr9B remains elusive. Importantly, $C f$ $9 B$ encodes 27 LRR and, thus, is more structurally related to $C f-9$ than $C f-4$ is to $C f-9$. Therefore, it is potentially a better template than $\mathrm{Cf}-4$ to address the role of residues in LRR 11 and 12 in determining Cf-9 specificity. Five amino acids were identified as the major determinants of Cf-9 specificity. These residues are putatively solvent exposed in the central LRR, occupy hypervariable positions in the global Hcr9 alignment, and overlap with the positions of those residues that determine Cf-4 specificity.

\section{RESULTS}

\section{Identification of Cf-9 specificity determinants by analysis of $\mathrm{Cf}-4 / \mathrm{Cf}-9$ chimeras.}

We previously reported that the major specificity-determining residues of Cf-9 appear to lie within LRR 10-18 (Wulff et al. 2001). Within these LRR, it was found that substitution of the residue $\mathrm{A}_{433}$ in LRR 15 of Cf-9 with the corresponding $\mathrm{T}$ in Cf-4 caused significantly reduced Avr9-dependent hypersensitive response (HR), and substitution of $\mathrm{L}_{457}$ in LRR 16 of Cf-9 with the corresponding $\mathrm{F}$ in $\mathrm{Cf}-4$ abolished function (Van der Hoorn et al. 2001b; Wulff et al. 2001). Wulff and associates (2001) also reported that substitution of amino acid $\mathrm{K}_{511}$ of $\mathrm{Cf}$ 9 in LRR 18 with $\mathrm{N}$ of $\mathrm{Cf}-4$ abolished function, which is in disagreement with the results of Van der Hoorn and associates (2001b) and Chakrabarti and associates (2009). Further work has subsequently revealed that the allele used by Wulff and associates (2001) had an additional mutation $\left(S_{448} L\right.$ in LRR 15) that abolished function, and our results are now in agreement with Van der Hoorn and associates (2001b) and Chakrabarti and associates (2009) (data not shown). Therefore, the major Cf-9 specificity-determining residues appear to lie within LRR 10 to 16 .

To identify additional Cf-9 specificity determinants within LRR 10 to 16, we first analyzed additional clones from our previously published Cf-4/Cf-9 shuffled library (Wulff et al. 2001). These analyses further confirmed that Cf-9 specificity lies within LRR 10 to 16 and that Cf-9 function requires the presence of LRR 11 to 12, which are deleted in Cf-4. These confirmatory studies are shown in the Supplementary Information published online. Analysis of these gene-shuffled chimeras did not, however, allow Cf-9 specificity to be further defined.

\section{Analysis of Cf-9/9B chimeras reveal four critical Cf-9 specificity-determining residues in LRR 13 to 15.}

To identify additional Cf- 9 specificity residues and to address the role of specificity within LRR 11 to 12 , we chose to use $C f-9 B$ as a template for comparison with $C f-9$ because it is a functional paralog that has the same number of LRR as Cf-9. Cf-9 and Cf-9B are $91 \%$ identical. There are 90 amino acid polymorphisms between Cf-9 and Cf-9B distributed through domains $A$ to $\mathrm{G}$, and there is a deletion of three amino acids in Cf-9 LRR 11 relative to $9 \mathrm{~B}$ and a deletion of one amino acid in Cf-9B domain B relative to Cf-9 (Fig. 1A).

$C f-9 / 9 B$ chimeras were generated between the ATG (domain A) and the internal HindIII site in LRR 21 (Fig. 1A) by gene shuffling (discussed below). This region does not encompass all polymorphisms between $\mathrm{Cf}-9$ and $\mathrm{Cf}-9 \mathrm{~B}$ but it does encompass all polymorphisms between Cf-4 and Cf-9 (Supplementary Fig. S1).

Sixty-two $C f-9 / 9 B$ shuffled clones were screened by Agrobacterium-mediated transient assays in leaves of Avr9 Nicotiana tabacum plants. The Cf-9-Avr9 gene-for-gene interaction can be recapitulated in this heterologous system; recognition between the transiently expressed Cf-9 protein and the stably expressed Avr9 results in an HR leading to a quantifiable necrosis (Thomas et al. 2000; Van der Hoorn et al. 2000), which correlates with restriction of pathogen growth in tomato (Wulff et al. 2001). Two $C f-9 / 9 B$ shuffled clones that induced an HR were identified and sequenced (Fig. 1B). Clone Shuf[7.13] induces a strong Avr9-dependent HR only slightly weaker than that of Cf-9. It is highly chimeric but encodes most of LRR 10 of Cf-9B, including the first six of nine Cf-9B amino acids polymorphic between Cf-9B and Cf-9 in this LRR (Fig. 1B). Therefore, these six amino acids do not appear to be important Cf-9 specificity determinants. Therefore, amalgamating this result with the results of the Cf-4/Cf- 9 analysis carried out previously (Van der Hoorn et al. 2001b; Wulff et al. 2001) suggests that the major Cf-9 specificity-determining residues lie within LRR 10.5 to 16 . However, the comparison between Cf-9 and Cf-9B narrows this down to LRR 10.5 to 15 , because there are no polymorphisms between Cf-9 and Cf-9B in LRR 16 (Fig. 1A). Indeed, by fusing the N-terminal half of Cf-9 to the C-terminal half of Cf-9B in LRR 15, a construct with only a slightly diminished Avr9-dependent HR was obtained, confirming that the major Cf- 9 specificity determinants are N-terminal of LRR 15 and that there are none C-terminal of this LRR (Fig. 1B, construct Cf-9[15]9B). This conclusion is further supported by the reciprocal domain swap where the $\mathrm{N}$-terminal half of $\mathrm{Cf}-9 \mathrm{~B}$ is fused to the $\mathrm{C}$-terminal half of $\mathrm{Cf}$ 9, which results in a construct with no Avr9-dependent HRinducing activity (Fig. 1B, construct 9B[15]Cf-9). 


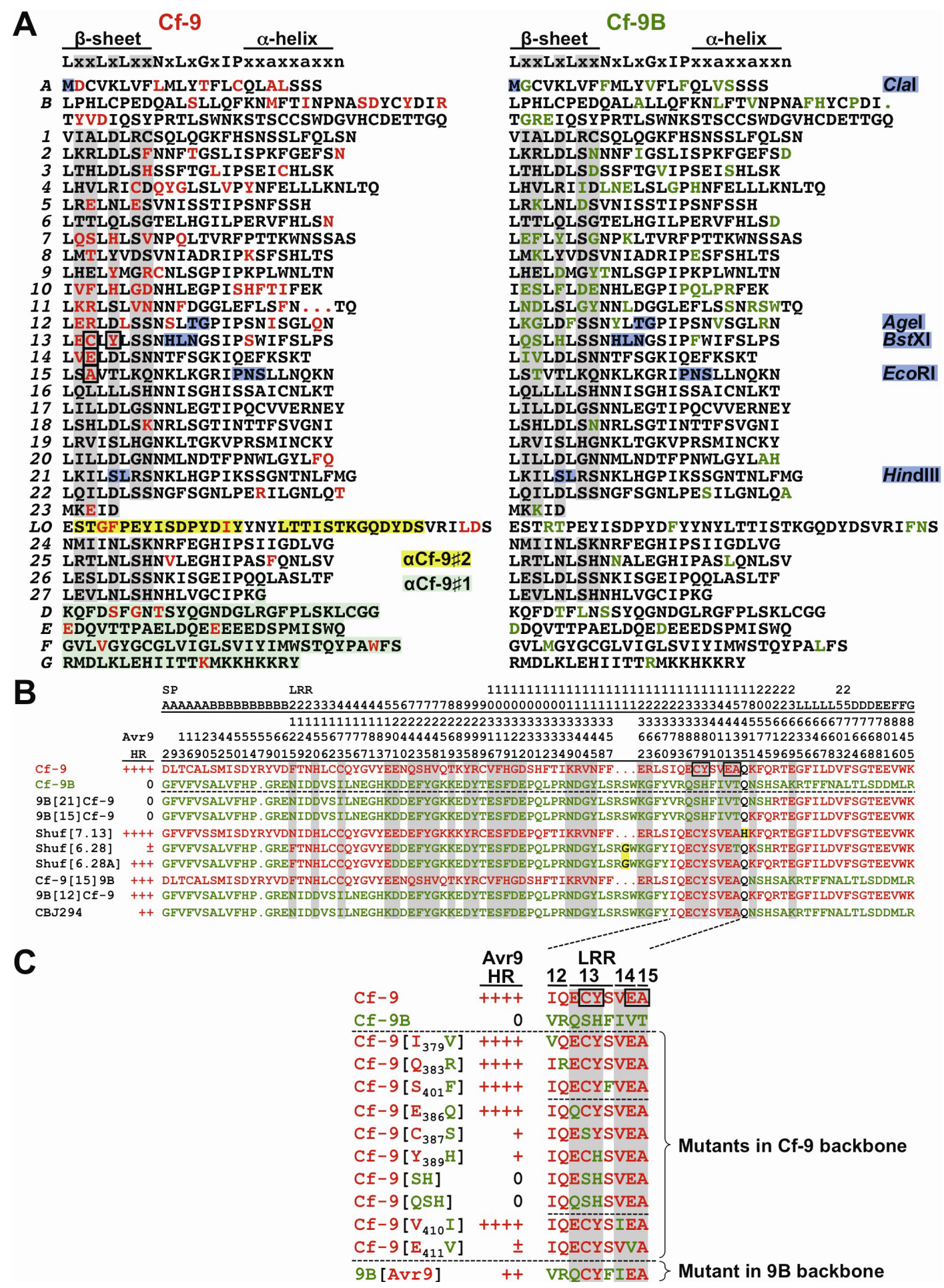

Fig. 1. Comparison of Cf-9 and Cf-9B and hypersensitive response (HR)-inducing activity of mutant constructs used to identify Cf-9 specificity-determining residues. A, Comparison of the Cf-9 and Cf-9B proteins. Polymorphic residues are shown in red (Cf-9) and green (Cf-9B). Structural domains of Hcr9 proteins (Jones and Jones 1997) are indicated on the left (A, signal peptide; B, $\alpha$-helical domain; D, domain without conspicuous features; E; acidic domain; F; trans membrane domain; G, basic domain; LO, loop out; leucine-rich repeats [LRR] are numbered 1 to 27). Conserved residues in the plant extracellular LRR structural motif (top) are indicated and putative solvent-exposed residues (x) in the $\beta$-strand/ $\beta$-turn structural motif ("LxxLxLxx") typical of LRR proteins are highlighted in gray (Jones and Jones 1997; Kobe and Deisenhofer 2001). Deletions in Cf-9 relative to 9B, and vice versa, are indicated by dots. Cf-9 residues that confer Avr9 recognition specificity are boxed (this study). The location of restriction enzyme sites that facilitated the cloning of shuffled sequences and the engineering of domain swaps are highlighted in blue. Peptides used for raising polyclonal antibodies against Cf- 9 are highlighted in green and yellow. B and C, Cf-9/9B chimeras and their Avr9-dependent HR-inducing activity. Only residues polymorphic between Cf-9 (red) and Cf-9B (green) are shown. Their location within domain A (A) the putative signal peptide (SP), domain B (B), the LRR (numbered), and the loop-out (L) are indicated in the upper panel. Vertical numbers refer to the amino acid position in the alignment relative to Cf-9. Amino acids that correspond to putative solvent-exposed residues of the LRR $\beta$-strand/ $\beta$-turn structural motif are highlighted in gray. The $C f-9 / 9 B$ chimeras are listed on the left hand side of the figure. The Avr9-dependent HR-inducing activity of each chimera is indicated with + (++++, wild-type activity; +++, approximately $75 \%$ of wild type; ++, approximately $50 \%$ of wild type; + , approximately $25 \%$ of wild type; \pm threshold activity; 0 , no activity). Shuffling-mediated polymerase chain reaction mutations are highlighted in yellow. Each construct was tested in at least three independent experiments. The construct CBJ294 (Chakrabarti et al. 2009) is depicted here for ease of comparison. 
We next constructed domain swap clones between Cf-9 and Cf-9B to further narrow down the Cf-9 specificity region within LRR 11 to 15. To this end, an AgeI site was introduced at homologous positions in sequences encoding LRR 12 of Cf9 and Cf-9B (Fig. 1A). This did not affect the amino acid sequence of $\mathrm{Cf}-9$ or $\mathrm{Cf}-9 \mathrm{~B}$ or the function of $\mathrm{Cf}-9$ (data not shown). This allowed the construction of domain-swap clone 9B[12]Cf-9, in which the N-terminal half of $\mathrm{Cf}-9 \mathrm{~B}$ is fused to

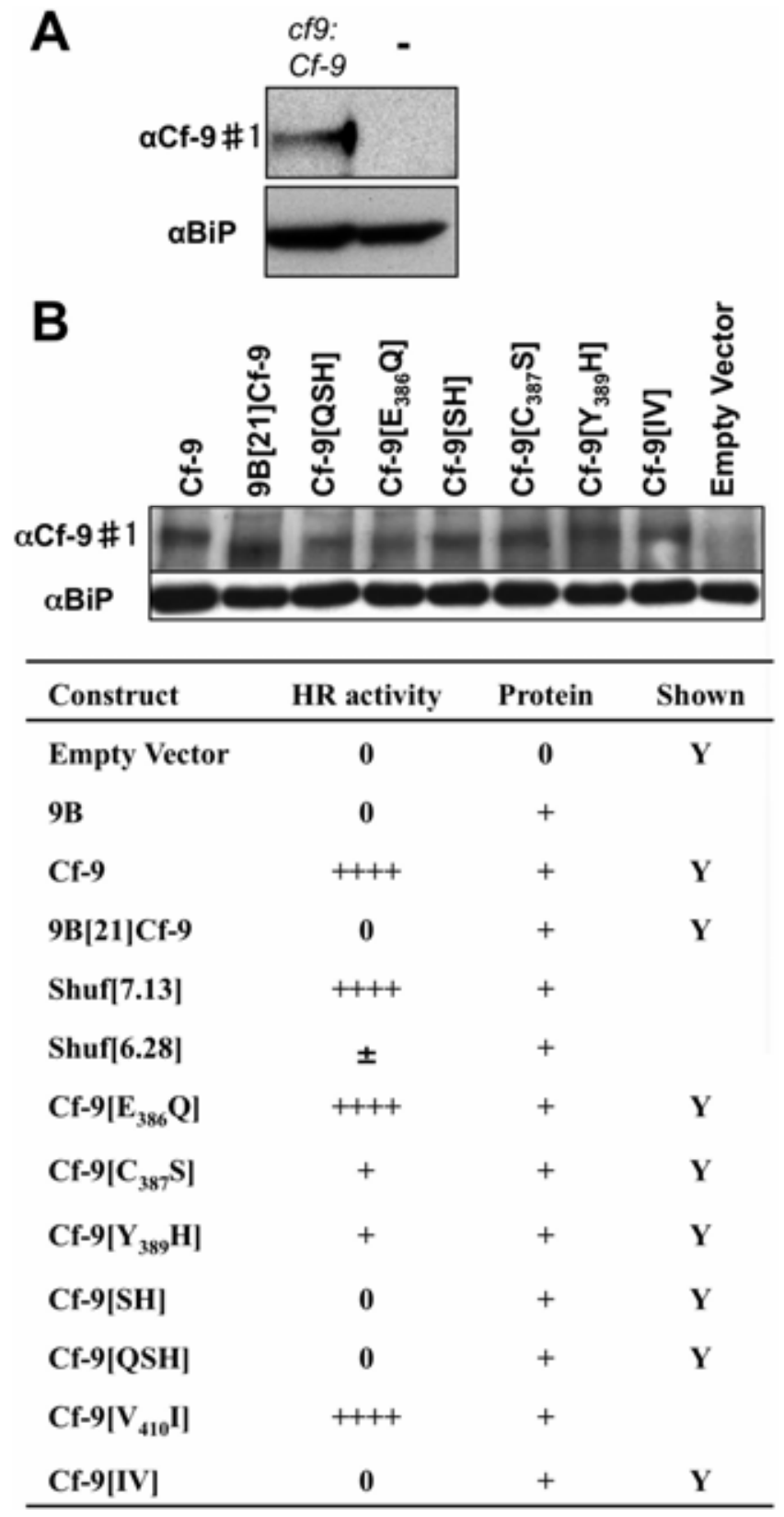

Fig. 2. Protein accumulation and Avr9-dependent hypersensitive responseinducing activity of Cf-9, Cf-9B, and chimeric proteins. A, An antibody raised against Cf-9 ( $\alpha \mathrm{Cf}-9 \# 1)$ recognizes a protein of approximately 150 $\mathrm{kDa}$, the expected size of Cf-9, specifically in Nicotiana tabacum plants expressing Cf- 9 driven by the native promoter $(c f-9 / C f-9)$ but not in nontransgenic control plants (-). B, Total proteins were prepared from N. tabacum Avr9 leaves 1 day postinoculation with Agrobacterium cultures to transiently express Cf-9B, Cf-9, chimeric constructs, or empty vector, and probed with the $\alpha \mathrm{Cf}-9 \# 1$ antibody. Equal loading is depicted by probing the lower part of the blots with anti-BiP. The lower apparent molecular weight of $9 \mathrm{~B}[21] \mathrm{Cf}-9$ compared with $\mathrm{Cf}-9$ is consistent with a net difference of three additional putative glycosylation sites in Cf-9 compared with Cf-9B (equivalent to approximately $8.5 \mathrm{kDa}$ or $9 \%$ of the total mass of Cf9) (Van der Hoorn et al. 2005). the C-terminal half of Cf-9 within LRR 12 (Fig. 1B). The Avr9-dependent HR of 9B[12]Cf-9 is only slightly diminished compared with Cf-9. This suggests that the major specificitydetermining residues do not reside between domain $\mathrm{A}$ and the first half of LRR 12 but, rather, appear to reside between the second half of LRR 12 and LRR 15. Indeed, a Cf-9B construct with LRR 12.5 to 15 replaced by Cf-9 gives an Avr9-dependent HR (Fig. 1B, construct CBJ294) (Chakrabarti et al. 2009).

Within LRR 15 , the only polymorphism between Cf-9 and Cf-9B is a putative solvent-exposed alanine-to-threonine substitution in the $\beta$-strand/ $\beta$-turn of the LRR motif (Fig. $1 \mathrm{~A}$ and B, $\mathrm{A}_{433} \mathrm{~T}$ ). In the analysis of the Cf-4/Cf-9 shufflants, this alanine was identified as a major Cf-9 specificity-contributing residue because substitution with the corresponding amino acid from Cf-4 (also a threonine, as in Cf-9B) resulted in clones with a significantly diminished Avr9-dependent HR (Wulff et al. 2001). This result may explain that the Cf-9/9B shuffled clone Shuf[6.28] only gives a barely detectable Avr9-dependent HR because, within LRR 13 to 15 , it contains the $\mathrm{A}_{433} \mathrm{~T}$ substitution (Fig. 1B). However, the interpretation for the loss of function of Shuf[6.28] is complicated by the observation that it contains a shuffling-induced mutation in LRR 12 (Fig. 1B). To address this problem, we fused the N-terminus of Shuf[6.28] to Cf-9 in LRR 13 to create Shuf[6.28A], which no longer contains the threonine-to-alanine substitution (Fig. 1B). The Avr9-dependent HR-inducing activity was restored in Shuf[6.28A], suggesting that the lack of activity of Shuf[6.28] is not due to the mutation in LRR 12 but rather highlighting again the importance of $\mathrm{A}_{433}$ as a Cf-9 specificity-determining residue. These data narrow down the putative specificity-determining region to nine polymorphic residues in LRR 12 to 15 , consistent with previous results showing that the putative solvent-exposed $A_{433}$ in LRR 15 is an important Cf-9 specificity determinant (Wulff et al. 2001).

To identify additional Cf-9 specificity-determining residues within this region, we focused our attention on the remaining eight polymorphic residues in LRR 12, 13, and 14 using sitedirected mutagenesis to change these residues in Cf- 9 into the corresponding residues of Cf-9B. Five of these residues are putatively solvent exposed in the $\beta$-strand/ $\beta$-turn of the LRR motif on the concave side of the protein and, therefore, available for ligand interaction (Fig. 1C). The other three are predicted to be buried in the hydrophobic core of the protein or on the convex side of the protein and, thus, less likely to participate in ligand interaction. When these latter three residues were substituted one by one, this did not impair the Avr9-dependent HRinducing activity (Fig. 1C, constructs Cf-9 $\left[\mathrm{I}_{379} \mathrm{~V}\right]$, Cf- $9\left[\mathrm{Q}_{383} \mathrm{R}\right]$, and Cf-9 $\left[\mathrm{S}_{401} \mathrm{~F}\right]$ in LRR 12 and 13). However, substitutions of the three putative solvent-exposed residues in LRR 13 with the corresponding residues in Cf-9B resulted in a severely diminished Avr9-dependent HR-inducing activity in the case of $\mathrm{C}_{387} \mathrm{~S}$ and $\mathrm{Y}_{389} \mathrm{H}$ but not in the case of $\mathrm{E}_{386} \mathrm{Q}$ (Fig. 1C). When $\mathrm{C}_{387} \mathrm{~S}$ and $\mathrm{Y}_{389} \mathrm{H}$ were combined in the double mutant, the Avr9-dependent HR was completely abolished (Fig. 1C. Cf-9[SH]).

In LRR 14, substitution of the two putative solvent-exposed residues with the corresponding residues in $\mathrm{Cf}-9 \mathrm{~B}$ resulted in no effect on activity in the case of $\mathrm{V}_{410} \mathrm{I}$, whereas $\mathrm{E}_{411} \mathrm{~V}$ had a significantly reduced Avr9-dependent HR-inducing activity (Fig. 1C). In summary, the critical Cf-9 specificity-determining residues identified are all putatively solvent exposed and reside in $\operatorname{LRR} 13\left(\mathrm{C}_{387}\right.$ and $\left.\mathrm{Y}_{389}\right), 14\left(\mathrm{E}_{411}\right)$, and $15\left(\mathrm{~A}_{433}\right)$, when comparing Cf-9 with Cf-9B.

\section{Loss of HR-inducing activity}

in null mutants is not due to reduced protein stability.

To exclude the possibility that the loss in HR observed for the Cf9/9B alleles generated in this study was due to reduced or lack of Cf-9/9B protein expression, we probed total proteins 
prepared from $N$. tabacum Avr9 leaves transiently expressing Cf-9/9B mutant constructs with a Cf-9 antibody ( $\alpha$ Cf-9\#1). This antibody was raised against the $\mathrm{D}$ to $\mathrm{G}$ domain of Cf-9, a region comprising 105 amino acids and containing eight polymorphisms between Cf-9 and Cf-9B (Fig. 1A). When examining well-characterized $N$. tabacum plants expressing $C f-9$ under its native promoter (line SLJ8808) (Hammond-Kosack et al. 1998), the $\alpha \mathrm{Cf}-9 \# 1$ antibodies crossreacted with a protein band of the expected apparent molecular mass of approximately $150 \mathrm{kDa}$ (Fig. 2A, $c f-9: C f-9$ ). No protein with a similar apparent molecular mass was detected in control plants that did not express Cf-9, confirming the specificity of the $\alpha \mathrm{Cf}-9 \# 1$ antibodies (Fig. 2A, -). Importantly, all tested mutant alleles, including seven mutants with no or significantly diminished HR-inducing activity, accumulated mutant proteins to $\mathrm{Cf}-9$ wild-type levels based on the qualitative assessment of four different transient expression experiments (Fig. 2B). These results demonstrated that loss-of-function mutants are not simply due to reduced expression or loss of protein stability but, rather, are due to loss of specificity. This is consistent with previous analyses of TAP-tagged Cf-4/Cf-9 chimeric constructs (Van der Hoorn et al. 2003).

\section{A Cf-9B mutant containing}

Cf-9 specificity-determining residues recognizes Avr9.

To investigate to what extent the four Cf-9 specificity-determining residues, namely $\mathrm{C}_{387}$ (LRR13), $\mathrm{Y}_{389}$ (LRR 13), $\mathrm{E}_{411}$ (LRR 14), and $\mathrm{A}_{433}$ (LRR 15), contribute to Cf-9 specificity, the codons encoding $\mathrm{Cf}-9 \mathrm{~B}$ residues at these positions were mutated to encode those of Cf-9. The resulting construct, 9B[Avr9] (Fig. 1C), was expressed side by side with nonmutated Cf-9B and Cf-9 in transgenic Avr9 N. tabacum. Only Cf9 and 9B[Avr9] gave an HR, and this HR was dependent on the presence of Avr9 (Fig. 3A; data not shown). The HR-inducing activity of the 9B[Avr9] gain-of-function construct appeared less than that of wild-type Cf-9. To quantify the activity of $9 \mathrm{~B}$ [Avr9] relative to $C f-9$, serial dilutions of both constructs with empty vector were expressed side by side in $\mathrm{N}$. $\mathrm{ta}$ bacum Avr9 leaves and the HR quantified according to the method of Van der Hoorn and associates (2000) (Fig. 3B). Based on 14 independent experiments and quantifications, the 9B[Avr9] gain-of-function construct was found to have an average of $21 \%$ ( $\pm 3 \%$ standard error) of the activity of Cf-9, indicating that some but not all $\mathrm{Cf}-9$ specificity-contributing residues have been identified in this study.

Although the construct 9B[Avr9] containing the four Cf-9 specificity-determining residues from LRR 12.5 to 15 in the Cf-9B backbone induced an Avr9-dependent HR, chlorosis was occasionally observed with this construct when expressed in N. tabacum control plants without Avr9 (Fig. 3A). This Avr9-independent chlorosis was not observed when all nine variant residues in LRR 12.5 to 15 were introduced into Cf-9B

Fig. 3. Mutant Cf-9B protein containing the Cf-9 specificity-determining residues confers an Avr9-dependent hypersensitive response (HR). A, Four Cf-9 specificity-determining residues polymorphic between Cf-9 and Cf9B, when introduced into Cf-9B (construct 9B[Avr9]), confer an Avr9dependent HR (upper panel) and an occasional weak Avr9-independent chlorosis in Nicotiana tabacum (lower panel). B, Activity of 9B[Avr9] was quantified in relation to Cf-9 by serial dilutions of each construct with Agrobacterium-carrying empty vector (i.e., no $C f$ gene). HR in the image shown in A, top panel is quantified. Based on 14 independent quantifications, the average activity of 9B[Avr9] was determined at approximately $21 \%$ ( $\pm 3 \%$ standard error) that of Cf-9 (insert), indicating that there are additional specificity-contributing residues outside leucinerich repeats 13 to 15 .
(Fig. 2, construct CBJ294 (Chakrabarti et al. 2009). Therefore, it appears that the variant residues between 9B[Avr9] and CBJ294 can promote a weak autoactivation in 9B[Avr9].

Hcr9 autoactivation can vary between species of Nicotiana (Wulff et al. 2004a). In general, it was found that autoactivators with low HR activity in N. tabacum displayed high autoactivity in $N$. benthamiana and, vice versa, autoactivators with high activity in $N$. tabacum displayed low activity in $N$. ben-

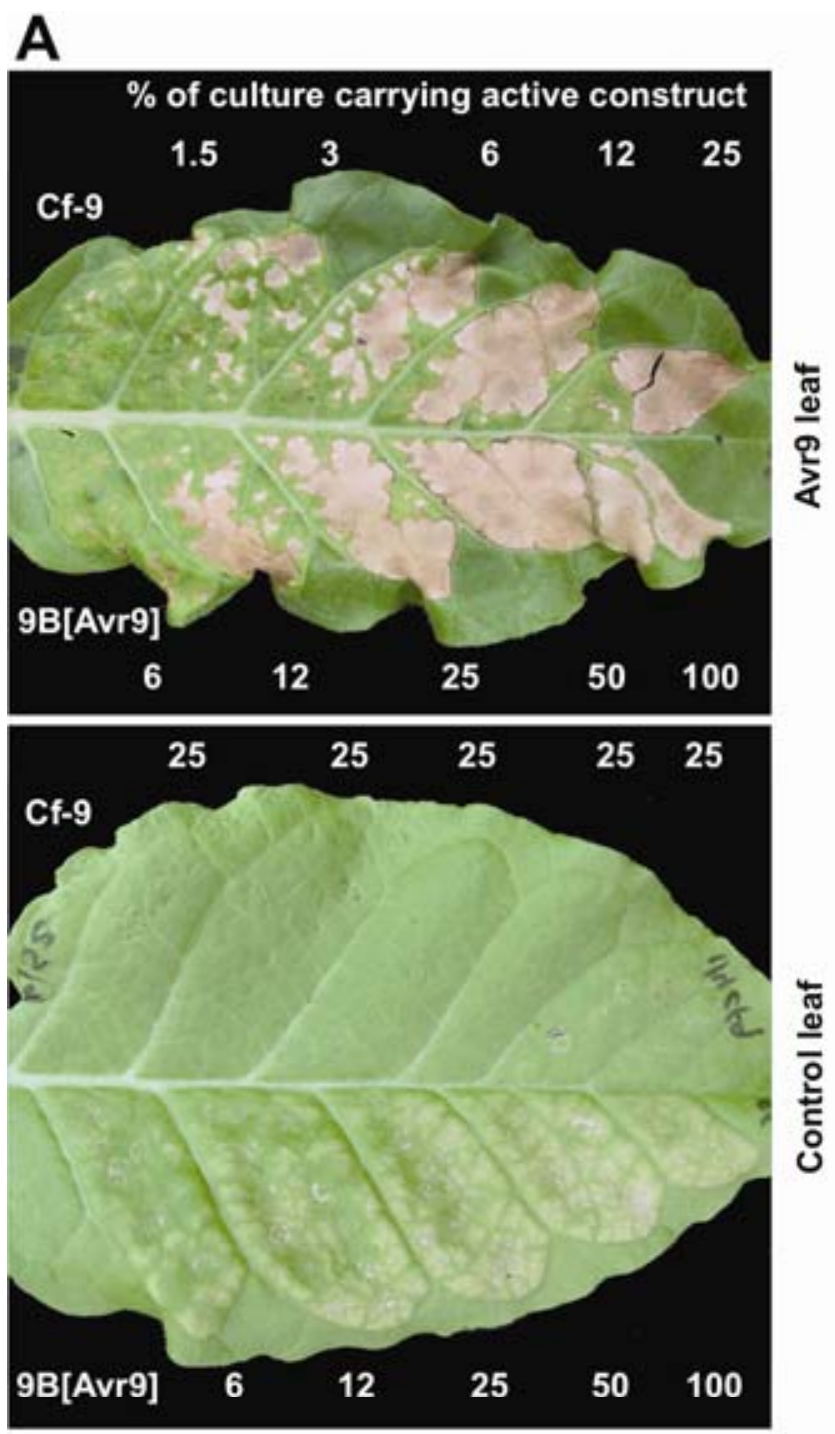

B

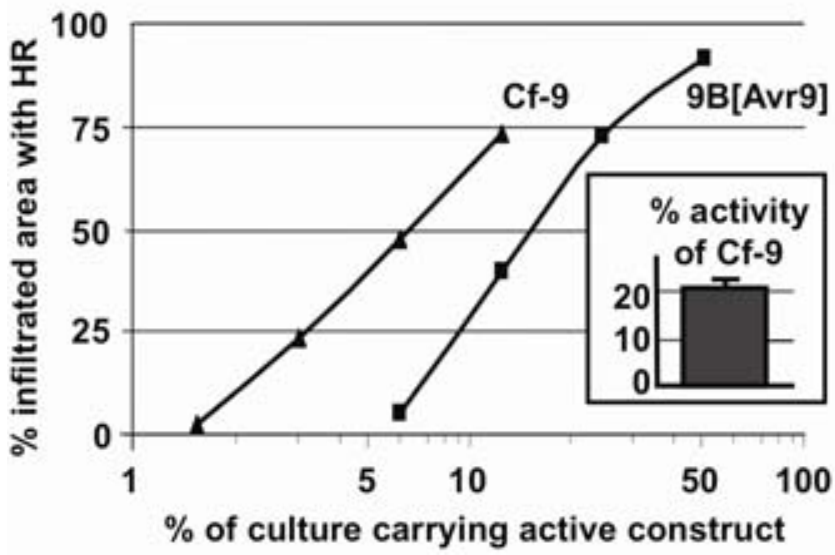

Vol. 22, No. 10, 2009 / 1207 
thamiana (Wulff et al. 2004a). Therefore, we tested the ability of 9B[Avr9] to induce an HR in N. benthamiana. In mature leaves of 5-week-old plants, 9B[Avr9] gave an HR only when co-expressed with Avr9 (Fig. 4A), indicating that the HRinducing activity of 9B[Avr9] is Avr9-dependent in both $N$. tabacum and $N$. benthamiana. Consistent with our previous observations, expression of Cf-9B in the absence of Avr9 induced a chlorosis with occasional chlorotic flecks (Wulff et al. 2004a), and this was also the case for 9B[Avr9] (Fig. 4A].

To exclude the possibility that the observed functional activity of 9B[Avr9] was due to enhanced protein accumulation, we probed total extracts prepared from $N$. benthamiana leaves transiently expressing Cf-9, 9B, 9B[Avr9], or empty vector with a Cf-9 antibody raised against the loop-out domain of $\mathrm{Cf}$ 9 (Fig. 1A, $\alpha \mathrm{Cf}-9 \# 2$ ). A protein with the expected apparent molecular weight of approximately $150 \mathrm{kDa}$ was detected in leaves transiently expressing Cf-9, 9B, and 9B[Avr9] but not in empty-vector-expressing plants, confirming the specificity of the antibody (Fig. 4B). Importantly, 9B[Avr9] protein was found to accumulate to levels similar to Cf-9 and 9B (Fig. 4B), indicating that the functional activity of $9 \mathrm{~B}[\mathrm{Avr} 9]$ is not due to enhanced protein accumulation but, rather, enhanced recognition of Avr9.

\section{DISCUSSION}

\section{Putative solvent-exposed residues}

in LRR 13 to 16 determine Cf-9 specificity.

In the present study, Cf-9 specificity was analyzed by making chimeras between Cf-9 and its close paralog, Cf-9B, which

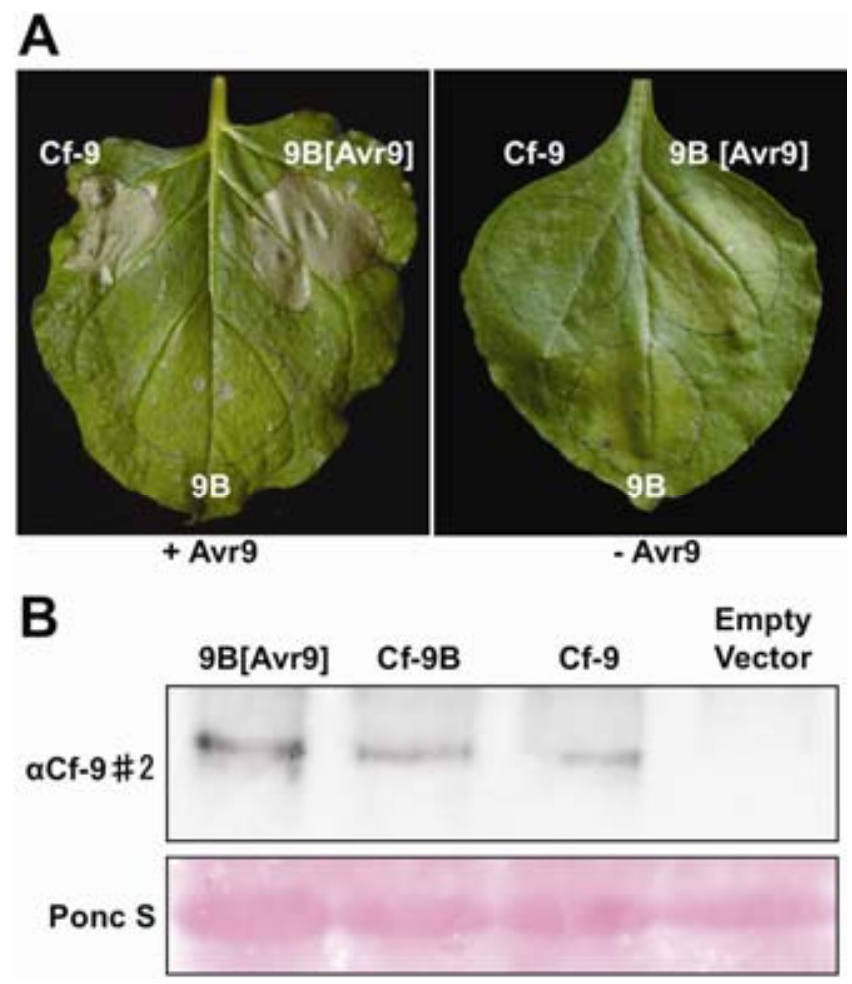

Fig. 4. Hypersensitive response (HR)-inducing activity and protein accumulation of 9B[Avr9] in Nicotiana benthamiana. A, Construct 9B[Avr9] confers a confluent HR in $N$. benthamiana only when co-expressed with Avr9, whereas chlorosis and occasional necrotic flecks can be observed in the absence of Avr9. The assay was performed three times with similar results. B, Total proteins were prepared from $N$. benthamiana leaves 3 days postinoculation with Agrobacterium cultures to transiently express Cf-9, Cf-9B, 9B[Avr9], or empty vector, and probed with the $\alpha \mathrm{Cf}-9 \# 2$ antibody. Equal loading is depicted by staining the blot with Ponceau S. is $91 \%$ identical to Cf-9 yet does not recognize Avr9. The chimeras were tested for their ability to generate an Avr9-dependent HR when transiently expressed in N. tabacum. Candidate features important for Cf-9 specificity were identified according to the hypothesis that i) amino acids which can be substituted with Cf-9B without significantly reducing activity are not important for Cf-9 specificity whereas, conversely, ii) amino acids which reduce activity significantly when substituted are important for Cf-9 specificity. Subsequently, the protein stability of a subset of Cf-9/9B chimeras, including four nonfunctional proteins, was analyzed, and all were found to accumulate to wild-type levels, suggesting that loss of function is not due to loss of protein accumulation but, likely, due to loss of protein specificity. This rationale allowed us to home in on LRR 12.5 to 15 as likely to contain important determinants of Cf-9 specificity, because all other LRR could be interchanged with those of Cf-9B without severely compromising Cf-9 function (Fig. 1B). Mutational analysis of the nine amino acids variant between Cf-9 and Cf-9B in LRR 12.5 to 15 allowed identification of four amino acids in LRR 13, 14, and 15 which, when mutated in $\mathrm{Cf}-9$ to encode the corresponding amino acids in Cf-9B, significantly reduced Cf-9 activity with little or no effect on protein stability. Importantly, when these Cf-9 amino acids were all introduced into Cf-9B, this Cf-9B mutant was now able to generate an Avr9-dependent HR (Figs. 1C and 3, mutant 9B[Avr9]), demonstrating that the identified amino acids alone or in combination confer Avr9-recognitional specificity. Although the functional capacity of 9B[Avr9] to confer C. fulvum resistance was not tested in this study, we have previously observed a strict correlation between the HR-inducing activity of Cf-4/Cf- 9 chimeras in transient assays in N. tabacum plants and restriction of pathogen growth in transgenic tomato for all analyzed constructs (Wulff et al. 2001).

A fifth amino acid important to Cf-9 specificity was identified in LRR 16 ( $\left.\mathrm{L}_{457}\right)$, based on a polymorphism with Cf-4 (Van der Hoorn et al. 2001b; Wulff et al. 2001). The importance of this residue could not be revealed in the present comparison between Cf-9 and Cf-9B because they are identical at this position. These five major Cf- 9 specificity-determining amino acids are all putatively solvent exposed in the $\beta$-strand $/ \beta$-turn motif of the concave side of the LRR and, thus, available for ligand interaction (Fig. 5). Conversely, in LRR 13 to 16, none of the three Cf-9/9B variant amino acids predicted to project into the hydrophobic core of the protein or to lie on the convex side of the protein were found to contribute to Cf-9 specificity (Fig. 1C). The Cf-9 specificity-determining residues are conserved in all seven other Hcr9s that recognize Avr9 (Supplementary Fig. S2) (Kruijt et al. 2004, 2005; Van der Hoorn et al. 2001a) confirming the importance of these residues in determining Avr9 recognition specificity.

Based on previous studies with chimeras between Cf-9 and $\mathrm{Cf}-4$, it was concluded that the major specificity determinants of Cf-9 were distributed evenly throughout LRR 1 to 16 (Van der Hoorn et al. 2001b; Wulff et al. 2001). For example, swapping LRR 1 to 5,6 to 10 , or 13 to 16 of Cf- 4 into Cf-9 resulted in chimeras with no or only a barely detectable Avr9-dependent HR (Van der Hoorn et al. 2001b). These contradictory results might be explained by differences in the templates used to analyze Cf- 9 specificity; namely, Cf-4 in the previous studies and $\mathrm{Cf}-9 \mathrm{~B}$ in the present study. Indeed, there are many polymorphisms between Cf-4 and Cf-9B in LRR 4 and 5. Furthermore, and consistent with a role of the distal N-terminal LRR in Avr9 recognition, we did consistently observe a slight reduction in the Avr9-dependent HR when the N-terminus of Cf-9B was fused to Cf-9 in LRR 12 (Fig. 1B, mutant $9 \mathrm{~B}[12] \mathrm{Cf}-9)$. In addition, fusion of the N-terminus of Cf-9 to 
Cf-9B in LRR 15 also resulted in a slight reduction in the Avr9-dependent HR (Fig. 1B, mutant Cf-9[15]9B), indicating a contribution of residues C-terminal to LRR 15 in Avr9 recognition. The observation that the activity of the Cf-9B gain-offunction construct 9B[Avr9] is approximately $21 \%$ that of Cf-9 also confirms the importance of additional residues that contribute to Avr9 recognition outside of LRR 13 to 16. The contribution of these residues on an individual basis may be so minor that they could be difficult to identify by making single amino acid substitutions. At any rate, these observations from Cf-9/Cf-4 and Cf-9/9B comparisons suggest that the Cf- 9 protein interaction surface is large or that substitutions outside the central LRR can impinge indirectly on the structure of the central specificity region by intramolecular effects.

The positions of $\mathrm{Cf}-4$ and $\mathrm{Cf}-9$ specificity-determining residues overlap and are hypervariable.

It was previously shown that the major Cf-4 specificitydetermining residues are three putative solvent-exposed amino acids in LRR 13, 14, and 16 (namely, $\mathrm{W}_{389}, \mathrm{G}_{411}$, and $\mathrm{F}_{457}$ ) (Fig. 5) (Van der Hoorn et al. 2001b). When these residues

\section{Cf-4}

$\frac{\beta \text {-sheet }}{L \times \text { XxLxxNxLxGxIPxxaxxaxxn }}$

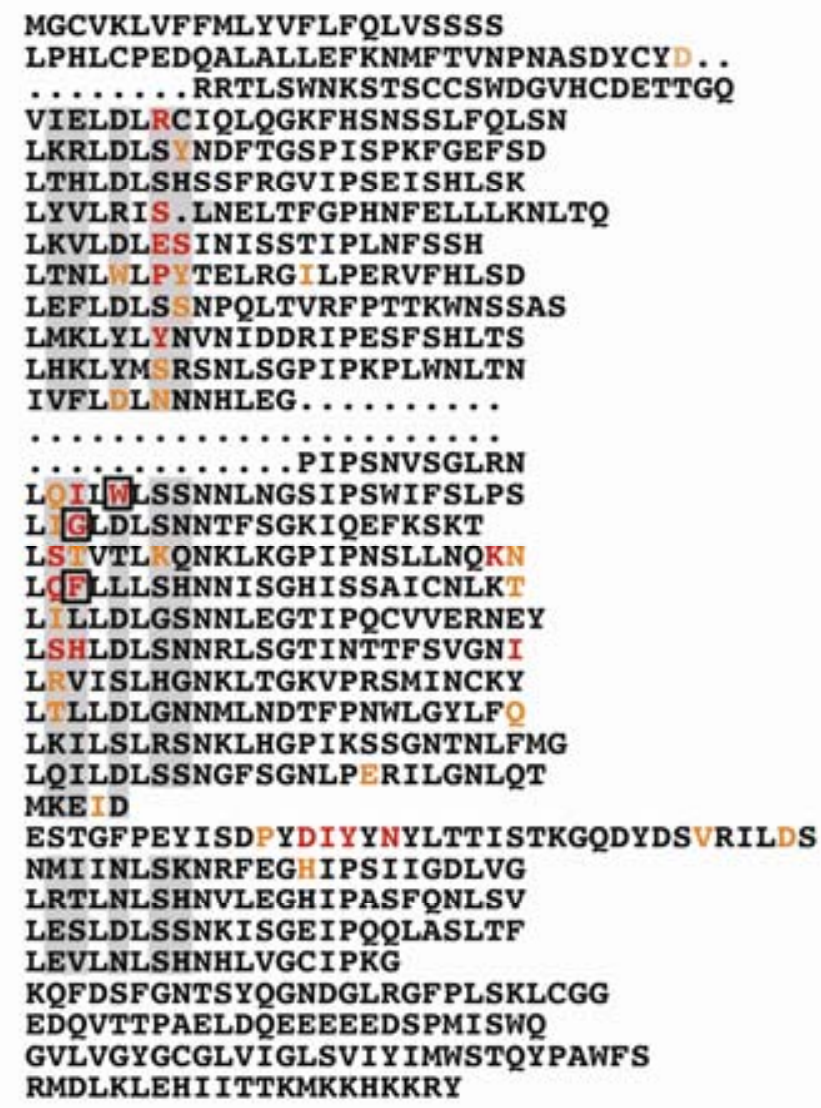

\section{Legend: 1-4 amino acids 5-6 amino acids 7-9 amino acids \\ Specificity residue}

were introduced at the corresponding positions in a modified $C f-9$ backbone containing domain B of $C f-4$, and LRR 11 to 12 deleted, this resulted in a clone recognizing Avr4 (Van der Hoorn et al. 2001b). The major determinants of Cf-9 specificity identified in this study were five putative solvent-exposed residues in LRR 13, 14, 15, and 16 (namely, $\mathrm{C}_{387}, \mathrm{Y}_{389}, \mathrm{E}_{411}$, $\mathrm{A}_{433}$, and $\mathrm{L}_{457}$ ) (Fig. 1). Interestingly, these residues cluster in the same region of the LRR and completely overlap with the determinants of $\mathrm{Cf}-4$ specificity (Figs. 5 and 6C through E). Thus, it would appear that the bulk of variant amino acids in Hcr9 proteins do not appear to contribute to specificity. Of the 90 variant amino acids between Cf- 9 and Cf-9B, 5 are enough to change the specificity of Cf-9B to Cf-9 (this study) and, of the 67 amino acids variant between Cf- 4 and Cf-9, only 3 are major determinants of Cf-4 specificity (Van der Hoorn et al. $2001 b$ ). The finding that, of the five Cf-9 specificity-determining residues identified, three occupy the exact same position as the Cf- 4 specificity-determining residues precludes the possibility of a molecule with dual specificity. It would be interesting to extend this study to other Hcr9 proteins for which the cognate fungal elicitor has been cloned (e.g., Hcr9-4E) and de-

\section{Cf-9}

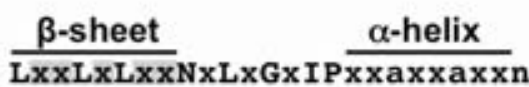

MDCVKLVFLMLYTFLCQLALSSS

LPHLCPEDQALSLLQFKNMFTINPNASDYCY I R

TY VD IQSYPRTLSWNKSTSCCSWDGVHCDETTGQ

VIALDLRCSQLQGKFHSNSSLFQLSN

LKRLDLS NNFTGSLISPKFGEFSN

LTHLDLSHSSFTGLIPSEICHLSK

LHVLRICDQYGLSLVPYNFELLLKNLTQ

LRELNLESVNISSTIPSNFSSH

LTTL LS TELHG I LPERVFHLSN

LQSLHLS NPQLTVRFPTTKWNSSAS

LMTLYVDSVNIADRIPKSFSHLTS

LHELYM RCNLSGPIPKPLWNLTN

IVFL $L$ DNHLEGPISHFTIFEK

L RLSL NNNFDGGLEFLSFN . . . TQ

LERLDLSSNSLTGPIPSNISGLQN

L C GSSNHLNGSIPSWIFSLPS

L EDLSNNTFSGKIOEFKSKT

LS OTL QNKLKGRIPNSLLNQKN

LQD LLSHNN ISGH ISSAICNLKT

L ILDLGSNNLEGTIPQCVVERNEY

LSHLDLSKNRLSGTINTTFSVGNI

L VISLHGNKLTGKVPRSMINCKY

L LLDLGNNMLNDTFPNWLGYLF $O$

LKILSLRSNKLHGPIKSSGNTNLFMG

LQILDLSSNGF SGNLPERILGNLQT

MKEID

ESTGFPEYISDPYDIYYNYLTTISTKGQDYDSVRILDS

NMI INLSKNRFEGH IPS I I GDLVG

LRTLNLSHNVLEGHIPASFQNLSV

LESLDLSSNKISGEIPQQLASLTF

LEVLNLSHNHLVGCIPKG

KOFDSFGNTSYQGNDGLRGF PLSKLCGG

EDQVTTPAELDOEEEEEDSPMISWO

GVLVGYGCGLVIGLSVIYIMWSTQYPAWFS

RMDLKLEHI ITTKMKKHKKRY

Fig. 5. Amino acid sequence and location of specificity-determining residues of the tomato Cf- 4 and Cf-9 proteins. Structural domains of Hcr9 proteins are indicated as in Figure 1A. Residues are colored to illustrate the number of different amino acids found at the same location when the sequences of 39 Hcr9 proteins were compared; red $=7$ to 8 amino acids; orange $=5$ to 6 amino acids; black $=1$ to 4 amino acids. Note that the hypervariable (red) and variable (orange) amino acids concentrate at the putative solvent-exposed residues. Amino acids that determine the specificity of Cf-4 (Van der Hoorn et al. $2001 \mathrm{~b}$ ) and Cf-9 (this study) are boxed. Residues deleted in Cf-4 relative to Cf-9, and vice versa, are shown by dots. 
termine to what extent localization of the major specificitydetermining residues in the central LRR is a general feature of Hcr9 proteins. Because Avr9B has not yet been identified, we were unable to investigate Cf-9B specificity of the Cf-9/9B chimeras in the present study.

By aligning $11 \mathrm{Hcr} 9$ proteins, it was previously reported that most of the variant amino acid positions are found in the putative solvent-exposed positions in the $\beta$-strand/ $\beta$-turn of the LRR motif of LRR 1 to 16 (Parniske et al. 1997). We updated this analysis by including an additional 28 Hcr 9 sequences, which have since been cloned (Fig. 5), and depicted the variable amino acid positions on to the 3D structural model of Cf-9 developed by Van der Hoorn and associates (2005) (Fig. 6A). This analysis clearly shows that diversity in the LRR sequences is concentrated at the concave inner surface of the protein, and that this diversity concentrates in the putative solvent-exposed positions in the $\beta$-strand/ $\beta$-turn of LRR 4 to 18 (Figs. 5 and 6A). The loop-out between LRR 23 and 24 was also found to be extremely variable (Figs. 5 and 6A). The loop-out has been proposed to act as a molecular hinge between the two LRR domains (Van der Hoorn et al. 2005), perhaps allowing Cf-9 to take on a conformational change during ligand interaction. In contrast, in the brassinosteroid receptor BRI1 and the phyto- sulfokine receptor PSKR, the loop-outs were recently shown to bind directly with their respective ligands (Kinoshita et al. 2005; Shinohara et al. 2007).

The major Cf-4 and Cf-9 specificity-determining residues in LRR 13 to 16 were found to occupy some of the most variable positions (Fig. 5), indicating a strong diversifying selection at key specificity-determining positions. Hcr9s evolve by shuffling and diversifying selection at the putative solvent-exposed residues of the $\beta$-strand/ $\beta$-turn loop of the LRR motif (Parniske et al. 1997). Analysis of the alignment of $39 \mathrm{Hcr} 9$ proteins indicated that the $\mathrm{Cf}-4$ specificity-determining residue $\mathrm{G} 411$ and the Cf-9 specificity-determining residue C 387 are specific to Cf- 4 and Cf-9 or their respective variants. This reinforces the idea (Van der Hoorn et al. 2001b) that mutation followed by selection, rather than recombination with other Hcr9s, has been a crucial evolutionary force in the generation of the $\mathrm{Cf}-4$ and Cf-9 specificities.

The identified Cf- 4 and Cf- 9 specificity-determining residues occupy predominantly the second x position in the LxxLxLxx motif (Fig. 5, four of five positions). In contrast, a scanning mutagenesis of the Arabidopsis FLAGELLIN SENSING2 (FLS2) protein identified the third and fourth positions as being most important for FLS2 binding of bacterial flagellin
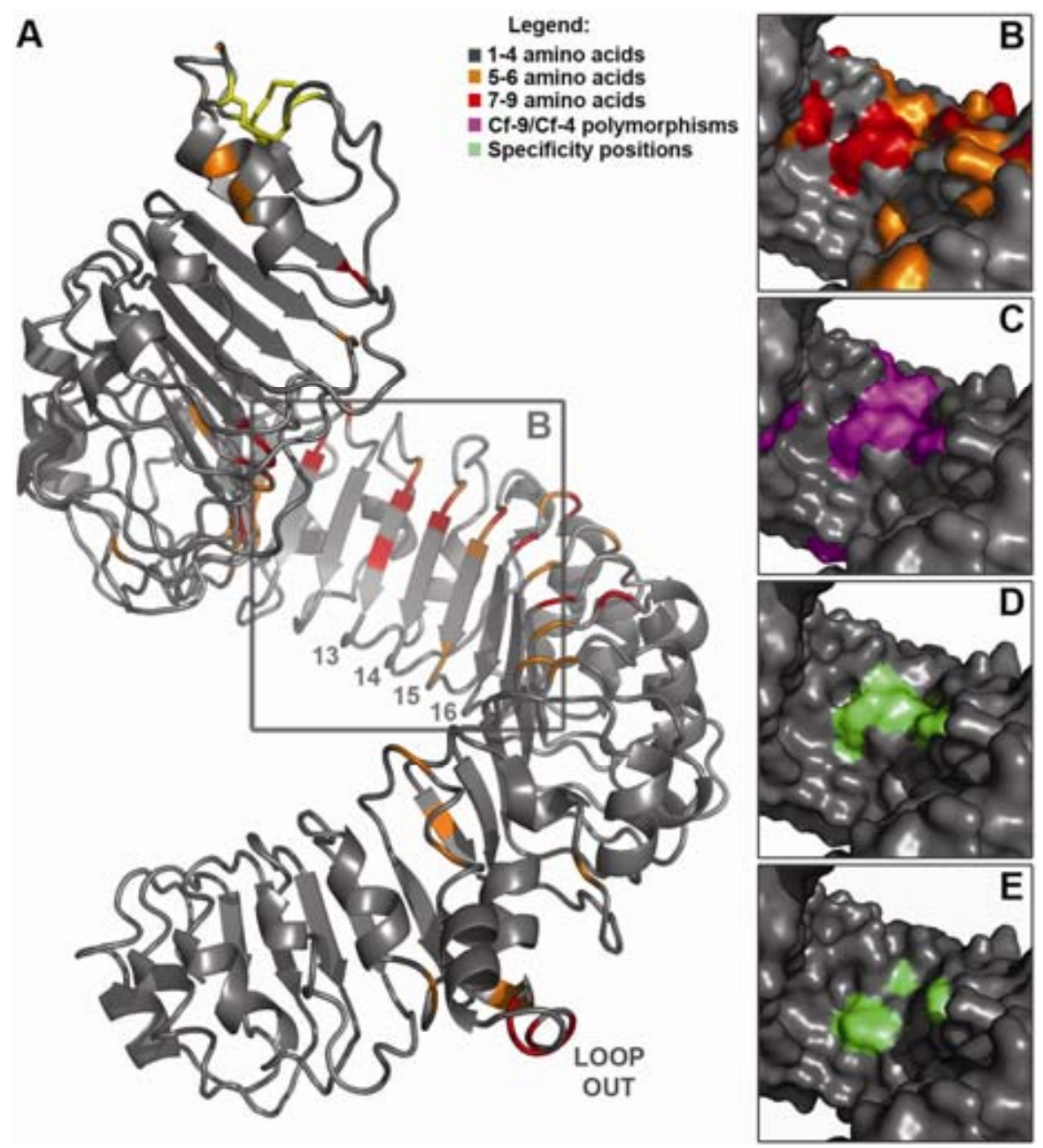

Fig. 6. Location of polymorphic and specificity-determining residues in the Cf-9 protein. A, Side view of the Cf-9 structural model (Van der Hoorn et al. 2005) shown with residues highlighted according to the degree of polymorphism found at each position when 39 Hcr9 proteins are compared. Note the high degree of polymorphism in the $\beta$-sheet of the inner surface of the protein. Leucine-rich repeats (LRR) 13 to 16 are labeled and $\mathbf{B}$, shown as an enlarged surface model, illustrating the Cf-9 specificity-determining residues colored as in A. C, Surface model of LRR 13 to 16 of Cf-9 showing, in magenta, those residues that are different to Cf-4. Surface model of LRR 13 to 16 of D, Cf-9 and E, Cf-4 with the solvent-exposed specificity-determining residues highlighted in green. E, Cf-4 LRR were threaded onto the Cf-9 model and the Cf-4 specificity-determining residues are highlighted. Disulfide bonds are shown with yellow sticks in A. 
(Dunning et al. 2007). These differences between Cf-4/9 and FLS2 may hint at differences in the docking of their respective ligands.

\section{Models for Cf-9 protein function.}

The current guard hypothesis for $\mathrm{R}$ protein ligand perception proposes that some $\mathrm{R}$ proteins do not detect their cognate pathogen effector molecules directly. In the guard model, some $\mathrm{R}$ proteins guard the virulence targets of pathogen effectors and detect an enzymatic or conformational change of the virulence target caused by the effector (Jones and Dangl 2006).

In the case of Cf-9 and Avr9, the apparent lack of direct interaction (Luderer et al. 2001) points to indirect detection of Avr9 through interaction with an Avr9-binding partner. In favor of this hypothesis, an Avr9 high-affinity binding site (HABS) has been detected in plasma membranes of tomato and other Solanaceous species, independently of the presence of Cf-9 (Kooman-Gersmann et al. 1996). Importantly, the HABS may be required for Cf- 9 function because a direct correlation between Avr9 binding and Cf-9 defense responses has been observed (de Jong et al. 2002; Kooman-Gersmann et al. 1998). These data suggest that Cf- 9 recognizes the presence of Avr9 indirectly by sensing the interaction of Avr9 with the HABS.

It is intriguing, however, to note that the small size of the Avr9 peptide and the close proximity of the major Cf- 9 specificity-determining residues within only four LRR (Figs. 1 and 5) do not exclude a model based on direct interaction. These two disparate models for Cf-9-Avr9 interaction can be accommodated by a third, intermediate model, in which Cf- 9 guards the HABS and Avr9 co-interacts with the HABS and Cf-9 LRR 13 to 16.

In contrast to the high sequence similarity between $\mathrm{Cf}-4$ and Cf-9, there is no sequence similarity between the corresponding fungal avirulence genes Avr4 and Avr9 (de Wit and Joosten 1999). The mature Avr4 protein consists of 86 amino acids whereas mature Avr9 contains only 28 amino acids. The threedimensional structure of Avr9 has been determined, revealing a cysteine knot protein composed of three anti-parallel $\beta$ strands, two solvent-exposed loops, and three disulfide bridges (Veervoort et al. 1997). No function has been ascribed to Avr9 but it seems likely that it may promote virulence by perturbing the operation of the HABS. There is no HABS for Avr4 in the plasma membrane of tomato but Avr4 has been shown to be a chitin-binding protein that protects the cell wall of $C$. fulvum during infection (Van den Burg et al. 2006; Van Esse et al. 2007).

Given the high similarity of Cf-4 and Cf-9 and the apparent different natures of their cognate elicitors, it is curious that the specificity-determining residues of Cf- 4 and Cf- 9 completely overlap in a short region (Fig. 6D and E). To what extent the central LRR contribute to specificity in other functional Hcr9s is an exciting question which merits further research. If the concentration of major specificity-determining residues in the central LRR does turn out to be a general feature of Hcr9 proteins, then this knowledge might be exploited in the artificial evolution of genes with novel specificities by creating $\mathrm{Hcr} 9$ libraries specifically mutated in these regions and screening against defined elicitors.

\section{MATERIALS AND METHODS}

\section{DNA manipulation.}

Frequent-cutting restriction endonucleases (RE) were used to fragment $C f-9$ and $C f-9 B$ DNA in preparation for shuffling. The complete digestion of the parental genes with different sets of RE was used to force overlap extension during the reas- sembly cycles to give rise to chimeric genes at high frequencies (Kikuchi et al. 1999). Cf-9/9B shufflants, domain-swap clones, and site-directed mutant constructs were cloned in the pBIN19-derived binary vector SLJ12904 in which expression is driven by the constitutive $35 \mathrm{~S}$ promoter (Wulff et al. 2001). Further details of the shuffling, domain-swap construction, and site-directed mutagenesis are provided in Supplementary Information published with this article online. All mutants were sequenced using the binary constructs as templates to exclude secondary polymerase chain reaction- or cloning-derived mutations.

\section{Computational alignment of $\mathrm{Hcr} 9 \mathrm{~s}$.}

The 39 available Hcr9 sequences (de Kock et al. 2005; Kruijt et al. 2004, 2005; Parniske and Jones 1999; Parniske et al. 1997; Wulff et al. 2004b) were computationally aligned after the following changes were made to restore open reading frames of pseudo $(\Psi)$ genes: "C" removed from position 499 in $\Psi N L A$; "T" removed from positions 452 and 1,085 in $\Psi N L B$; "G", "T", and "G" removed from positions 535, 536, and 1,755 in $\Psi S C B$; "A" and T" removed from positions 460 and 461 in $\Psi O R O A$; "A" removed from position 1,759 in $\Psi O R 5 A$; and a "C" added after position 770 in $\Psi 9 D C-9 E$.

\section{Cf-9 antibody production.}

A C-terminal fragment of $C f-9$ (Fig. 1) was amplified using the primer pairs Cf-9-D1s and Cf-9-G3a and subcloned into the BamHI site of pMalEHis containing an additional in-frame sequence encoding three histidines (provided by B. Feys). Correct sequence and in-frame fusion was confirmed by sequence analysis. Expression and isolation of the soluble fusion protein (maltose-binding protein [MBP]-His-Cf-9c) was done by affinity chromatography using amylose-resin according to the manufacturer's specifications (New England Biolabs, Hitchin, Hertfordshire, U.K.). The fusion protein was further separated from minor contaminants by sodium dodecyl sulfate polyacrylamide gel electrophoresis (SDS-PAGE), cut out, and sent to Eurogentec (Seraign, Belgium) for polyclonal antibody production in rabbits. Purification of the $\alpha \mathrm{Cf}-9 \# 1$ antibodies was performed by first depleting them of anti-MBP-His antibodies and subsequently purifying them against MBP-His-Cf9c fusion protein as described (Bar-Peled and Raikhel 1996), with the exception that amylose beads (New England Biolabs) were used to crosslink MBP-His and MBP-His-Cf9c fusion proteins. Prior to immunoblot analyses, $\alpha \mathrm{Cf}-9 \# 1$ antibodies were incubated for $4 \mathrm{~h}$ at room temperature with protein acetone powder obtained from $N$. tabacum leaves lacking Cf- 9 to further reduce cross-reactivity with nonspecific protein bands. A second Cf-9 antibody ( $\alpha \mathrm{Cf}-9 \# 2)$ was raised against two peptides of the loop-out domain (Fig. 1).

\section{Agrobacterium-mediated transient assays in N.tabacum and detection of mutant proteins with $\mathbf{C f}-\mathbf{9}$ antibody.}

Agrobacterium-mediated transient assays in $N$. tabacum were carried out as described previously (Thomas et al. 2000; Van der Hoorn et al. 2000). Material for protein immunoblot analysis was harvested from N. tabacum Avr9 leaves 1 day postinfiltration before the onset of HR. Total extracts were subjected to protein blot analysis using 7\% SDS-PAGE and $\alpha \mathrm{Cf}-9$ (1:300; current studies) and $\alpha \mathrm{BiP}(1: 20,000)$ (Fontes et al. 1991) as described previously (Heese et al. 2005).

\section{ACKNOWLEDGMENTS}

We thank P. L. Collins and K. E. Saville for help with characterization and screening of the $C f-9 / 9 B$ and $C f-4 / C f-9$ shuffled libraries; D. Alger and S. Perkins for horticultural assistance; C. Mills and C. M. Thomas (Uni- 
versity of East Anglia) for the plasmid SLJ21109; B. Feys (Imperial College, London, GB) for the pMalEHis expression vector; and R. Boston (North Carolina State University, Raleigh, U.S.A.) for the $\alpha$ BiP antibody. This work was funded by an European Molecular Biology Organization long-term fellowship to A. Heese. The Sainsbury Laboratory is supported by the Gatsby Charitable Foundation.

\section{LITERATURE CITED}

Bar-Peled, M., and Raikhel, N. V. 1996. A method for isolation and purification of specific antibodies to proteins fused to the GST. Anal. Biochem. 241:140-142.

Chakrabarti, A., Panter, S. N., Harrison, K., Jones, J. D. G., and Jones, D. A. 2009. Regions of the Cf-9B disease resistance protein able to cause spontaneous necrosis in Nicotiana benthamiana lie within the region controlling pathogen recognition in tomato. Mol. Plant-Microbe Interact. 22:1214-1226.

de Jong, C. F., Takken, F. L. W., Cai, X., de Wit, P. J. G. M., and Joosten, M. H. A. J. 2002. Attenuation of Cf-mediated defense responses at elevated temperatures correlates with a decrease in elicitor-binding sites. Mol. Plant-Microbe Interact. 15:1040-1049.

de Kock, M. J. D., Brandwagt, B. F., Bonnema, G., de Wit, P. J. G. M., and Lindhout, P. 2005. The tomato Orion locus comprises a unique class of Hcr9 genes. Mol. Breed. 15:409-422.

de Wit, P. J., and Joosten, M. H. 1999. Avirulence and resistance genes in the Cladosporium fulvum-tomato interaction. Curr. Opin. Microbiol. 2:368-373.

Di Matteo, A., Federici L., Mattei, B., Salvi, G., Johnson, K. A., Savino, C., De Lorenzo G., Tsernolou, D., and Cervone F. 2003. The crystal structure of polygalacturonase-inhibiting protein (PGIP), a leucine-rich repeat protein involved in plant defense. Proc. Natl. Acad. Sci. U.S.A. 100:10124-10128.

Dunning, F. M., Sun, W., Jansen, K. L., Helft, L., and Bent, A. F. 2007. Identification and mutational analysis of Arabidopsis FLS2 leucine-rich repeat domain residues that contribute to flagellin perception. Plant Cell 19:3297-3313.

Fontes, E. B. P., Shank, B. B., Wrobel, R. L., Moose, S. P., Obrian, G. R., Wurtzel, E. T., and Boston, R. S. 1991. Characterization of an immunoglobulin binding-protein homolog in the maize floury-2 endosperm mutant. Plant Cell 3:483-496.

Fritz-Laylin L. K., Krishnamurthy, N., Tör, M., Sjölander, K. V., and Jones, J. D. G. 2005. Phylogenomic analysis of the receptor-like proteins of rice and Arabidopsis. Plant Physiol. 138:611-623.

Hammond-Kosack, K. E., Tang, S., Harrison, K., and Jones, J. D. G. 1998 The tomato Cf-9 disease resistance gene functions in tobacco and potato to confer responsiveness to the fungal avirulence gene product avr9. Plant Cell 10:1251-1266.

Heese, A., Ludwig, A. A., and Jones J. D. G. 2005. Rapid phosphorylation of a syntaxin during the Avr9/Cf-9-race-specific signalling pathway. Plant Physiol. 138:2406-2416.

Jones, D. A., and Jones, J. D. G. 1997. The role of leucine-rich repeat proteins in plant defences. Adv. Bot. Res. Inc. Adv. Plant Pathol. 24:89167.

Jones, J. D. G., and Dangl, J. L. 2006. The plant immune system. Nature 444:323-329.

Joosten, M. H. A. J., and de Wit, P. J. G. M. 1999. The tomato-Cladosporium fulvum interaction: A versatile experimental system to study plantpathogen interactions. Annu. Rev. Phytopathol. 37:335-367.

Kikuchi, M., Ohnishi, K., and Harayama, S. 1999. Novel family shuffling methods for the in vitro evolution of enzymes. Gene 236:159-167.

Kinoshita, T., Caño-Delgado, A., Seto, H., Hiranuma, S., Fujioka, S., Yoshida, S., and Chory, J. 2005. Binding of brassinosteriods to the extracellular domain of plant receptor kinase BRI1. Nature 433:167-171.

Kobe, B., and Deisenhofer, J. 2001. The leucine-rich repeat as a protein recognition motif. Curr. Opin. Struct. Biol. 11:725-732.

Kooman-Gersmann, M., Honée, G., Bonnema, G., and de Wit, P. J. G. M. 1996. A high-affinity binding site for the Avr9 peptide elicitor of Cladosporium fulvum is present on plasma membranes of tomato and other solanaceous plants. Plant Cell 8:929-938.

Kooman-Gersmann, M., Vogelsang, R., Vossen, P., Van den Hooven, H. W., Mahé, E., Honée, G., and de Wit, P. J. G. M. 1998. Correlation between binding affinity and necrosis-inducing activity of mutant AVR9 peptide elicitors. Plant Physiol. 117:609-618.

Kruijt, M., Brandwagt, B. F., and de Wit, P. J. G. M. 2004. Rearrangements in the $C f-9$ disease resistance gene cluster of wild tomato have resulted in three genes that mediate Avr9 responsiveness. Genetics 168:1655-1663.

Kruijt, M., Kip, D. J., Joosten, M. H. A. J., Brandwagt, B. F., and de Wit, P. J. G. M. 2005. The $C f-4$ and $C f-9$ resistance genes against Cladospo- rium fulvum are conserved in wild tomato species. Mol. Plant-Microbe Interact. 18:1011-1021.

Leckie, F., Mattei, B., Capodicasa, C., Hemmings, A., Nuss, L., Aracri, B., De Lorenzo, G., and Cervone, F. 1999. The specificity of polygalacturonase-inhibiting protein (PGIP): A single amino acid substitution in the solvent-exposed $\beta$-strand/ $\beta$-turn region of the leucine-rich repeats (LRRs) confers new recognition capability. EMBO (Eur. Mol. Biol. Organ.) J. 18:2352-2363.

Luderer, R., Rivas, S., Nürnberger, T., Mattei, B., Van den Hooven, H. W., Van der Hoorn, R. A. L., Romeis, T., Wehrfritz, J.-M., Blume, B., Nennstiel, D., Zuidema, D., Vervoort, J., De Lorenzo, G., Jones, J. D.G., de Wit, P. J. G. M., and Joosten, M. H. A. J. 2001. No evidence for binding between resistance gene product Cf-9 of tomato and avirulence gene product AVR9 of Cladosporium fulvum. Mol. Plant-Microbe Interact. 14:867-876.

Panter, S. N., Hammond-Kosack, K. E., Harrison, K., Jones, J. D. G, and Jones, D. A. 2002. Developmental control of promoter activity is not responsible for mature onset of $C f-9 B$-mediated resistance to leaf mold in tomato. Mol. Plant-Microbe Interact. 15:1099-1107.

Parniske, M., and Jones, J. D. G. 1999. Recombination between diverged clusters of the tomato $C f-9$ plant disease resistance gene family. Proc. Natl. Acad. Sci. U.S.A. 96:5850-5855.

Parniske, M., Hammond-Kosack, K. E., Golstein, C., Thomas, C. M., Jones, D. A., Harrison, K., Wulff, B. B. H., and Jones, J. D. G. 1997. Novel disease resistance specificities result from sequence exchange between tandemly repeated genes at the $C f 4 / 9$ locus of tomato. Cell 91:821-832.

Rivas, S., and Thomas, C. M. 2005. Molecular interactions between tomato and the leaf mold pathogen Cladosporium fulvum Annu. Rev. Phytopathol. 43:395-436.

Seear, P. J., and Dixon, M. S. 2003. Variable leucine-rich repeats of tomato disease resistance genes Cf-2 and Cf-5 determine specificity. Mol. Plant Pathol. 4:199-202.

Shinohara, H., Ogawa, M., Sakagami, Y., and Matsubayashi, Y. 2007. Identification of ligand binding site of phytosulfokine receptor by oncolumn photoaffinity labeling. J. Biol. Chem. 282:124-131.

Shiu, S. H., Karlowski, W. M., Pan, R., Tzeng, Y. H., Mayer, K. F., and Li, W. H. 2004. Comparative analysis of the receptor-like kinase family in Arabidopsis and rice. Plant Cell 16:1220-1234

Thomma, B. P. H. J., van Esse H. P., Crous, P. W., and de Wit, P. J. G. M. 2005. Cladosporium fulvum (syn. Passalora fulva), a highly specialized plant pathogen as a model for functional studies on plant pathogenic Mycosphaerellaceae. Mol. Plant Pathol. 6:379-393.

Thomas, C. M., Jones, D. A., Parniske, M., Harrison, K., Balint-Kurti, P. J., Hatzixanthis, K., and Jones, J. D. G. 1997. Characterization of the tomato $C f-4$ gene for resistance to Cladosporium fulvum identifies sequences that determine recognitional specificity in Cf-4 and Cf-9. Plant Cell 9:2209-2224.

Thomas, C. M., Tang, S., Hammond-Kosack, K., and Jones, J. D. G. 2000. Comparison of the hypersensitive response induced by the tomato $C f-4$ and Cf-9 genes in Nicotiana spp. Mol. Plant-Microbe Interact. 13:465469.

Van den Burg, H. A., Harrison, S. J., Joosten, M. H. A. J., Vervoort, J., and de Wit, P. J. G. M. 2006. Cladosporium fulvum Avr4 protects fungal cell walls against hydrolysis by plant chitinases accumulating during infection. Mol. Plant-Microbe Interact. 19:1420-1430.

Van der Hoorn, R. A. L., Laurent, F., Roth, R., and de Wit, P. J. G. M. 2000. Agroinfiltration is a versatile tool that facilitates comparative analysis of $A v r 9 / C f-9$ and $A v r 4 / C f-4$ induced necrosis. Mol. PlantMicrobe Interact. 13:439-446.

Van der Hoorn, R. A. L., Kruijt, M., Roth, R., Brandwagt, B. F., Joosten, M. H. A. J., and de Wit, P. J. G. M. 2001a. Intragenic recombination generated two distinct $C f$ genes that mediate AVR9 recognition in the natural population of Lycopersicon pimpinellifolium. Proc. Natl. Acad. Sci. U.S.A. 98:10493-10498.

Van der Hoorn, R. A. L., Roth, R., and de Wit, P. J. G. M. 2001b. Identification of distinct specificity determinants in resistance protein $\mathrm{Cf}-4$ allows construction of a Cf-9 mutant that confers recognition of avirulence protein AVR4. Plant Cell 13:273-285.

Van der Hoorn, R. A. L., Rivas, S., Wulff, B. B. H., Jones, J. D. G., and Joosten, M. H. A. J. 2003. Rapid migration in gel filtration of the Cf-4 and $\mathrm{Cf}-9$ resistance proteins is an intrinsic property of $\mathrm{Cf}$ proteins and not because of their association with high-molecular-weight proteins. Plant J. 35:305-315.

Van der Hoorn, R. A. L., Wulff, B. B. H., Rivas, S., Durrant, M. C., van der Ploeg, A., de Wit, P. J. G. M., and Jones, J. D. G. 2005. Structurefunction analysis of Cf-9, a receptor-like protein with extracytoplasmic leucine-rich repeats. Plant Cell 17:1000-1015.

Van Esse, H. P., Bolton, M. D., Stergiopoulos, I., de Wit, P. J. G. M., and Thomma, B. P. H. J. 2007. The chitin-binding Cladosporium fulvum 
effector protein Avr4 is a virulence factor. Mol. Plant-Microbe Interact. 20:1092-1101.

Veervoort, J., Van den Hooven, H. W., Berg, A., Vossen, P., Vogelsang, R., Joosten, M. H. A. J., and de Wit P. J.G. M. 1997. The race-specific elicitor AVR9 of the tomato pathogen Cladosporium fulvum: A cysteine knot protein. Sequence specific ${ }^{1} \mathrm{H}$ NMR assignments, secondary structure and global fold of the protein. FEBS (Fed. Eur. Biochem. Soc.) Lett. 404:153-158.

Wulff, B. B. H., Thomas, C. M., Smoker, M., Grant, M., and Jones, J. D. G. 2001. Domain swapping and gene shuffling identify sequences re- quired for induction of an Avr-dependent hypersensitive response by the tomato Cf-4 and Cf-9 proteins. Plant Cell 13:255-272.

Wulff, B. B. H., Kruijt, M., Collins, P. L., Thomas, C. M., Ludwig, A. A., de Wit, P. J. G. M., and Jones, J. D. G. 2004a. Gene shuffling-generated and natural variants of the tomato resistance gene $C f-9$ exhibit different auto-necrosis-inducing activities in Nicotiana species. Plant J. 40:942956.

Wulff, B. B. H., Thomas, C. M., Parniske, M., and Jones, J. D. G. 2004b. Genetic variation at the tomato $C f-4 / C f-9$ locus induced by EMS mutagenesis and intralocus recombination. Genetics 167:459-470. 